\title{
Association Between Intimate Partner Violence and Child Maltreatment in a Representative Student Sample in Hong Kong
}

\author{
Ko Ling Chan ${ }^{1}$
}

\begin{abstract}
The study examined the prevalence of the co-occurrence of intimate partner violence (IPV) and child maltreatment (CM) to determine whether IPV is a factor associated with the latter. A total of 5,841 students from a representative sample of schools in Hong Kong were surveyed. The results show that the lifetime and preceding-year co-occurrence rates of IPV and CM were $12.3 \%$ and $3.6 \%$, respectively. IPV and parents' use of psychological aggression and corporal punishment led to increased odds of physical violence. This study suggests a need for the comprehensive assessment of IPV and CM.
\end{abstract}

\section{Keywords}

child maltreatment, co-occurrence, intimate partner violence

There is evidence that children exposed to domestic violence are more likely to have adjustment difficulties such as depression, anxiety, posttraumatic stress disorder (PTSD), aggression, social withdrawal, low self-esteem, and behavioral problems (Finkelhor, Ormrod, \& Turner, 2009; Grych, Jouriles, Swank, McDonald, \& Norwood, 2000; Margolin \& Gordis, 2000; O’Keefe, 1995; Shipman, Rossman, \& West, 1999). In particular, children who have witnessed intimate partner violence (IPV) have an increased likelihood of being the target of child maltreatment (CM; that is, physical abuse, psychological aggression, and neglect; Margolin, Gordis, Medina, \& Oliver, 2003; Margolin et al., 2009; McGuigan \& Pratt, 2001; Ross, 1996). A variety of possible mechanisms have been proposed to explain the linkage between CM and IPV (Slep \& O’Leary, 2005). Such co-occurrence can be understood as either

\footnotetext{
${ }^{1}$ University of Hong Kong, Pok Fu Lam, Hong Kong
}

\section{Corresponding Author:[AQ1]}

Ko Ling Chan, Department of Social Work and Social Administration, University of Hong Kong,

Pok Fu Lam Road, Hong Kong, Hong Kong.

Email: eklchan@hku.hk 
a within-individual phenomenon (e.g., a husband abuses his wife as well as their children), one occurring across individuals within the same family (e.g., a husband abuses his wife and she abuses their children), or both (e.g., a husband abuses his wife and they both abuse the children; Jouriles, McDonald, Slep, Heyman, \& Garrido, 2008). Although there is some support for a single-perpetrator model in which (male) violence is directed at both spouse and child (Appel \& Holden, 1998; Dixon, Hamilton-Giachritsis, Browne, \& Ostapuik, 2007), it is also possible that mothers who report husband-to-wife aggression have a higher rate of CM compared with those who do not (Margolin et al., 2003; Margolin et al., 2009). The increased child abuse potential among victimized women may be due to abused women's higher levels of distress and problems with others (C. E. Casanueva \& Martin, 2007).

Studies examining the prevalence of CM vary considerably in their findings, depending on the sample selected. Most research on the co-occurrence of IPV and CM has used shelter or clinical samples and has demonstrated a broad range of cooccurrence rates, from $18 \%$ to $67 \%$ (Jouriles et al., 2008). However, the prevalence rate is much lower in community samples, at around 6\% (Appel \& Holden, 1998; Margolin et al., 2003). The main reasons for this diversity are methodological differences, in particular definitions of child abuse, study design, sampling design, and the samples themselves. For example, research using a broad definition of physical child abuse (including pushes, slaps, and spankings) yields a relatively high prevalence rate, whereas research using narrower definitions shows lower rates (O’Keefe, 1995; Slep \& O’Leary, 2005). Furthermore, CM in clinical samples is frequently defined according to official reports from child protective services on illegal behaviors perpetrated by caregivers against children. In community samples, researchers have often expanded this definition to include physical punishment, which is perceived as normative by parents (Chaffin, 2006). Therefore, information about the problems of children collected from shelter samples may not be generalizable to other children exposed to domestic violence.

Using different subjects will lead to the collection of different information about the co-occurrence of IPV and CM in the family. Data derived from battered women may underestimate the prevalence of co-occurrence (Jouriles \& Norwood, 1995), or may underreport their own and their partners' violence against children because of the fear of social service intervention and concern about legal action against the batterer (Appel \& Holden, 1998; Chan, 2009b). Because domestic violence affects all family members, the results generated in most of the research available using battered women or parents as subjects should not be presumed to characterize all forms of family violence. To get a full picture, the most important victims - that is, children—should not be ignored. However, there are only a few studies available that use children as significant informants on family violence (Bourassa, 2007; Carlson, 1991; Chan, 2005; Finkelhor, Ormrod, \& Turner, 2007; Finkelhor et al., 2009; Leung, Wong, Chen, \& Tang, 2008; Margolin et al., 2009). This work indicates co-occurrence rates from $24.9 \%$ to $66 \%$.

Given that few studies use children's reports on parental violence against them in the context of IPV, the present study used a representative sample of Chinese children 
in Hong Kong, extending our knowledge of the IPV and CM co-occurrence rates. The study examines the factors associated with $\mathrm{CM}$, and in particular, investigates the relationship between IPV and CM. We hypothesize that the two are likely to be positively correlated. Certain types of family violence may be more salient for children, and children's self-reports provide a better estimate than that of other third parties of children's actual experiences of violence (Grych et al., 2000). Besides, the majority of the studies on the co-occurrence of IPV and CM were conducted in Western societies. This study will be one of the few studies to investigate this topic in a non-Western society. Chinese culture values family honor, face saving, and respect for parents; thus, Chinese people tend to keep family matters private to minimize conflicts that might bring shame to the family (Chan, 2009a). This may increase the difficulties for maltreated children to reveal their misfortunes and their ability to cope with the impact of violence.

\section{Method}

\section{Participants and Recruitment}

The study surveyed a representative sample of children enrolled in primary and secondary schools. Because it is undesirable to survey very young children, the sample was confined to pupils in Primary 4 to 6 (equivalent to Grades 4-6 in the United States) and Secondary 1 to 7 (equivalent to Grades 7-12, or middle and high school, in the United States), aged mostly from about 9 to 18 years.

A two-stage stratified random sampling design was adopted to take into account the possibility of differences in the characteristics of children and their families. For the first stage, stratified systematic sampling was used, resulting in the inclusion of 28 mainstream primary, 30 mainstream secondary, and 15 special schools. Of these 73 schools, 44 responded, giving a response rate of $60 \%$ at the school level. At the individual level, the participation rate was very high, giving a response rate of about $99 \%$. Such a high response rate is not uncommon in school-based surveys conducted with a Chinese population (e.g., 99.7\% in Leung et al., 2008). The characteristics of the schools participating in the study were compared with the schools that refused participation. No significant differences were found between them in terms of school size, geographic distribution, and types of schools, as well as the ranking of schools that represented students' academic performance.

For the second stage, a random sample of one class was selected from each grade. Class sizes of school enrollments are similar in all the publicly funded schools. All children in the classes selected, about 30 to 40 students in total, were invited to participate. A total of 5,841 students, comprising 1,506 mainstream primary, 3,962 mainstream secondary, and 373 special school students, were eventually surveyed. The study was approved by the ethics review board of the University of Hong Kong. The questionnaire was self-administered by the students inside the classroom. Informed consent was obtained from individual students after they had been told that their participation was voluntary. Approvals were also granted by school principals 
who were sanctioned by parents in deciding to participate in the study. Participants were informed that they could refuse to answer any of the questions or even discontinue their involvement at any time, and that no identifiable information would be kept. Anonymity and confidentiality were strictly preserved. All the participants were given a pocket-sized information card with information for services for victims of family violence. Students were encouraged to seek help if necessary.

\section{Measures}

Dependent variables. Twelve self-constructed items were used to measure the following factors: child-witnessed conflict between parents and their parents-inlaw (2 items), which were modified from the items used to measure in-law conflict in previous studies (Chan, Brownridge, Tiwari, Fong, \& Leung, 2008; Chan et al., 2009); child-witnessed physical violence and psychological aggression by the father or mother against his or her partner (4 items); and father's or mother's use of corporal punishment, physical violence, and psychological aggression against a child (6 items). The measures of CM, which included corporal punishment, physical violence, and psychological aggression, were referenced to the concepts used in the Parent-Child Conflict Tactics Scale (CTSPC; Straus \& Hamby, 1997; Straus, Hamby, Finkelhor, Moore, \& Runyan, 1998). Instead of asking all the items of the CTSPC, examples of corporal punishment, physical violence, and psychological aggression were given to help the subjects consider whether an incident had occurred for a given type of aggression. Examples of corporal punishment included spanking a child on the bottom with a bare hand or implement such as a belt, hairbrush, stick, or some other hard object, and slapping a child on the hand, arm, or leg. Examples of physical violence included throwing things at a child, pushing or shoving, grabbing, slapping, twisting an arm or the person's hair, hitting, choking, burning or scalding on purpose, using a knife or sharp weapon, and kicking. Examples of psychological aggression included insulting, shouting or yelling, spitting, destroying things belonging to the other person, threatening, and ignoring. Psychological aggression against a child included three additional examples: calling the child dumb or lazy or some similar name, the parents saying they would send the child away or kick him or her out of the house, and not providing meals. The responses to each item included never, happened over the lifetime of the intimate relationship, and happened in the year before the study.

Independent variables. A separate part of the questionnaire collected the demographic and socioeconomic characteristics of the respondents and their families. It included items asking for information about the respondent's gender, age, education level, and number of siblings; parents' marital status, employment status, and educational attainment; and whether any family members were receiving public financial assistance. 


\section{Statistical Analysis}

The demographic characteristics of the respondents were summarized. The assessments of the CM, IPV, and in-law conflict were compared by the exact likelihood ratio chi-square test (for categorical data) and a $t$ test (for continuous data).

Logistic regression was also used to predict the presence or absence of family conflict in the preceding year based on the demographic variables. Logistic regression is an appropriate technique for predicting a dichotomous dependent variable from a set of independent variables. An odds ratio (OR) greater than 1.00 indicates that the independent variable is associated with an increase in the odds of the dependent variable. The converse is true if the OR is below 1.00. The nominal level of significance was taken as 5\%, and SPSS Version 17 was used for the analysis.

\section{Results}

\section{Participant Characteristics}

Complete profiles were successfully collected for 5,841 children and their parents. Table 1 presents the demographic characteristics of the respondents. Nearly $36 \%$ of the children were aged 12 to 14 years, $30.7 \%$ were 15 to $17,25.1 \%$ were aged 9 to 11 , and $8.3 \%$ were 18 or older. All participants were in school, mainly Secondary 1 to 3 (37.9\%), Primary 4 to 6 (28.1\%), Secondary 4 to 5 (23.3\%), and Secondary 6 to 7 (10.6\%). About $78.5 \%$ of the child respondents had siblings. Most participants' parents were married (84.2\%), and 14.7\% were single. About $10 \%$ of the families were receiving public financial assistance, and $9.6 \%$ of the parents were unemployed.

Analyzing the participants' family factors, boys were more likely than girls to be the only child in the family, to live in families receiving public financial assistance, to be studying in Primary 4 to 6 and a special school, to have an unemployed mother, and to have both parents with a primary level or lower education.

\section{Prevalence of Family Violence and Conflict}

Table 2 presents the results of the lifetime and preceding-year prevalence of parental CM, IPV, and in-law conflict; it also includes an assessment of gender differences in reporting these forms of violence or conflict. The most pervasive form of CM was corporal punishment by parents (58.4\%), followed by psychological aggression (48.6\%) and physical violence (32.2\%). The types of violence most frequently experienced by a child in the preceding year of the study, however, were psychological aggression (28.4\%), corporal punishment (20.9\%), and physical violence (13.9\%). Significantly more girls than boys reported their mothers using psychological aggression against them, whereas the converse was true for a parent's use of corporal punishment and physical violence. 
Table 1. Demographic Characteristics of Respondents.

\begin{tabular}{|c|c|c|c|c|c|}
\hline & $n$ & Total (\%) & Male (\%) & $\begin{array}{c}\text { Female } \\
(\%)\end{array}$ & $\chi^{2}$ \\
\hline \multicolumn{6}{|l|}{ Age } \\
\hline $9-11$ & 1,462 & 25.1 & 25.3 & 24.8 & 0.084 \\
\hline $12-14$ & 2,091 & 35.9 & 35.5 & 36.3 & \\
\hline $15-17$ & 1,789 & 30.7 & 31.6 & 29.7 & \\
\hline 18 or above & 486 & 8.3 & 7.6 & 9.2 & \\
\hline \multicolumn{6}{|l|}{ Level of education } \\
\hline Primary 4-6 & 1,640 & 28.1 & 29.2 & 26.9 & $0.000^{\star * *}$ \\
\hline Secondary $1-3^{a}$ & 2,211 & 37.9 & 39.1 & 36.6 & \\
\hline Secondary $4-5^{b}$ & 1,360 & 23.3 & 23.2 & 23.5 & \\
\hline Secondary $6-7^{\mathrm{b}}$ & 617 & 10.6 & 8.5 & 13.0 & \\
\hline \multicolumn{6}{|l|}{ Parents' marital status } \\
\hline Married & 4,910 & 84.2 & 84.1 & 84.4 & 0.135 \\
\hline Divorced & 481 & 8.3 & 8.2 & 8.3 & \\
\hline Separated & 115 & 2.0 & 2.4 & 1.5 & \\
\hline Widowed & 158 & 2.7 & 2.5 & 3.0 & \\
\hline Single & 97 & 1.7 & 1.7 & 1.6 & \\
\hline NA & 67 & 1.1 & 1.1 & 1.2 & \\
\hline Have sibling & 4,542 & 78.5 & 76.8 & 80.4 & $0.001^{* * *}$ \\
\hline Receiving public financial assistance & 523 & 10.4 & 11.3 & 9.3 & $0.022^{*}$ \\
\hline Studying in special school & 373 & 6.4 & 9.8 & 2.5 & $0.000^{\star * *}$ \\
\hline Father unemployed & 203 & 4.4 & 4.2 & 4.6 & 0.565 \\
\hline Mother unemployed & 263 & 5.2 & 5.9 & 4.4 & $0.022^{*}$ \\
\hline \multicolumn{6}{|l|}{ Father's educational attainment } \\
\hline Primary level or lower & 729 & 12.5 & 12.6 & 12.4 & $0.001^{* * *}$ \\
\hline Secondary 1-3 & 1,140 & 19.6 & 18.8 & 20.4 & \\
\hline Secondary 4-5 & 1,222 & 21.0 & 20.8 & 21.2 & \\
\hline Secondary 6-7 & 190 & 3.3 & 3.1 & 3.5 & \\
\hline Tertiary or above & 616 & 10.6 & 9.4 & 11.9 & \\
\hline Don't know & 1,931 & 33.1 & 35.4 & 30.5 & \\
\hline \multicolumn{6}{|l|}{ Mother's educational attainment } \\
\hline Primary level or lower & 845 & 14.5 & 14.9 & 14.0 & $0.000 * * *$ \\
\hline Secondary 1-3 & 1,151 & 19.7 & 18.7 & 21.0 & \\
\hline Secondary 4-5 & 1,426 & 24.5 & 22.5 & 26.7 & \\
\hline Secondary 6-7 & 219 & 3.8 & 3.5 & 4.1 & \\
\hline Tertiary or above & 424 & 7.3 & 6.6 & 8.0 & \\
\hline Don't know & 1,763 & 30.3 & 33.8 & 26.2 & \\
\hline
\end{tabular}

${ }^{a}$ Equivalent to Grades 7 to 9 in the United States.

${ }^{\mathrm{b}}$ Equivalent to Grades 10 to 12 (or high school) in the United States.

${ }^{*} p<.05 .{ }^{* *} p<.01 .{ }^{* *} p<.001$. 
Table 2. Lifetime and Preceding-Year Prevalence of CM, IPV, and In-Law Conflict.

\begin{tabular}{|c|c|c|c|c|}
\hline \multirow[b]{3}{*}{ Types of violence and conflict } & \multirow[b]{3}{*}{ Lifetime (\%) } & \multirow[b]{3}{*}{ Total (\%) } & \multicolumn{2}{|c|}{ Preceding year (\%) } \\
\hline & & & \multicolumn{2}{|c|}{ Gender } \\
\hline & & & Male (\%) & Female (\%) \\
\hline $\begin{array}{r}\text { Parents' use of psychological } \\
\text { aggression against a child }\end{array}$ & 48.6 & 28.4 & 26.8 & $30.2^{\star \star}$ \\
\hline $\begin{array}{l}\text { Father's use of psychological } \\
\text { aggression }\end{array}$ & 38.7 & 20.9 & 21.2 & 20.5 \\
\hline $\begin{array}{l}\text { Mother's use of psychological } \\
\text { aggression }\end{array}$ & 39.3 & 21.0 & 19.2 & $23.0^{\star * \star}$ \\
\hline $\begin{array}{l}\text { Parents' use of corporal } \\
\text { punishment against a child }\end{array}$ & 58.4 & 20.9 & 21.9 & 19.8 \\
\hline $\begin{array}{l}\text { Father's use of corporal } \\
\text { punishment }\end{array}$ & 42.9 & 13.5 & 14.9 & $11.8^{\star \star \star}$ \\
\hline $\begin{array}{l}\text { Mother's use of corporal } \\
\text { punishment }\end{array}$ & 50.5 & 16.5 & 16.9 & 16.1 \\
\hline $\begin{array}{l}\text { Parents' use of physical violence } \\
\text { punishment against a child }\end{array}$ & 32.2 & 13.9 & 15.0 & $12.6^{\star \star}$ \\
\hline $\begin{array}{l}\text { Father's use of physical } \\
\text { violence }\end{array}$ & 22.2 & 8.9 & 10.0 & $7.7^{\star \star}$ \\
\hline $\begin{array}{l}\text { Mother's use of physical } \\
\text { violence }\end{array}$ & 24.6 & 9.4 & 9.8 & 8.8 \\
\hline $\begin{array}{l}\text { Witnessed psychological } \\
\text { aggression between parents }\end{array}$ & 45.8 & 27.8 & 25.5 & $30.4^{\star \star \star}$ \\
\hline $\begin{array}{l}\text { Witnessed father's use of } \\
\text { psychological aggression }\end{array}$ & 40.6 & 23.4 & 21.2 & $25.8^{\star \star \star}$ \\
\hline $\begin{array}{l}\text { Witnessed mother's use of } \\
\text { psychological aggression }\end{array}$ & 35.9 & 21.9 & 19.7 & $24.4^{\star \star \star}$ \\
\hline $\begin{array}{l}\text { Witnessed physical violence } \\
\text { between parents }\end{array}$ & 19.1 & 7.6 & 7.8 & 7.3 \\
\hline $\begin{array}{l}\text { Witnessed father's use of } \\
\text { physical violence }\end{array}$ & 16.7 & 6.1 & 6.2 & 6.0 \\
\hline $\begin{array}{l}\text { Witnessed mother's use of } \\
\text { physical violence }\end{array}$ & 11.9 & 4.7 & 5.2 & 4.2 \\
\hline $\begin{array}{l}\text { Witnessed parents' in-law } \\
\text { conflict }\end{array}$ & 31.0 & 14.1 & 13.7 & 14.6 \\
\hline $\begin{array}{l}\text { Witnessed father's in-law } \\
\text { conflict }\end{array}$ & 20.9 & 8.3 & 8.4 & 8.2 \\
\hline $\begin{array}{l}\text { Witnessed mother's in-law } \\
\text { conflict }\end{array}$ & 22.5 & 9.8 & 9.7 & 9.8 \\
\hline
\end{tabular}

Note. $\mathrm{CM}=$ child maltreatment; IPV = intimate partner violence.

${ }^{\star} p<.05 .{ }^{* *} p<.01 .{ }^{* \star *} p<.001$.

With regard to the prevalence of IPV witnessed by children, the lifetime and preceding-year prevalence rates of psychological aggression between the parents were $45.8 \%$ and $27.8 \%$, and for physical violence were $19.1 \%$ and $7.6 \%$, respectively. Significantly more girls than boys reported having witnessed their parents' use of psychological aggression against each other. Finally, the lifetime 
and preceding-year prevalence rates of parents' in-law conflict were $31 \%$ and $14.1 \%$, respectively. The rates for the use of CM, in-law conflict, and IPV were similar for both parents.

Table 3. Co-Occurrence of IPV (Witnessed Physical Violence and Psychological Aggression Between Parents) and CM (Parents' Use of Physical Violence and Psychological Aggression).

\begin{tabular}{lccccc}
\hline & $\begin{array}{c}\text { No abuse } \\
(\%)\end{array}$ & $\begin{array}{c}\text { IPV only } \\
(\%)\end{array}$ & \multicolumn{2}{c}{ CM only } \\
$(\%)$ & $\begin{array}{c}\text { Co-occurrence } \\
(\%)\end{array}$ & $\begin{array}{c}\text { \% of CM } \\
\text { among IPV }\end{array}$ \\
\hline $\begin{array}{l}\text { Lifetime prevalence } \\
\text { Physical violence }\end{array}$ & 61.2 & 6.7 & 19.8 & 12.3 & 64.7 \\
$\begin{array}{l}\text { Psychological aggression } \\
\text { Preceding-year prevalence }\end{array}$ & 39.8 & 11.6 & 14.4 & 34.2 & 74.7 \\
$\quad \begin{array}{l}\text { Physical violence } \\
\text { Psychological aggression }\end{array}$ & 82.2 & 3.9 & 10.3 & 3.6 & 48.0 \\
\hline
\end{tabular}

Note. IPV = intimate partner violence; $\mathrm{CM}=$ child maltreatment.

Table 3 shows the rates of co-occurrence of IPV and CM. The lifetime and preceding-year prevalence rates for physical violence were $12.3 \%$ and $3.6 \%$, respectively. For psychological aggression, the lifetime and preceding-year cooccurrence rates were $34.2 \%$ and $16 \%$, respectively. To present the figures differently, among those families characterized by physical violence between parents, $64.7 \%$ and $48 \%$ were involved in physical violence against a child in their lifetime and the preceding year of the study, respectively.

\section{Risk Factors}

Before regression analyses were performed, multicollinearity was checked among all independent variables to see whether they were highly correlated in a multiple regression model. The Variance Inflation Factor (VIF) measures how much the variance of a coefficient is increased because of collinearity. In this study, all VIFs were smaller than 2, indicating no multicollinearity problems (O’Brien, 2007).

Table 4 presents the bivariate and multivariate logistic regression results for the demographic characteristics associated with corporal punishment and physical violence against a child in terms of preceding-year prevalence. These analyses controlled for all the demographic covariates included in Table 4. Factors relevant to the child (e.g., being of a younger age) and family factors (e.g., receiving public financial assistance) were significantly associated with greater odds of parents' use of corporal punishment after covariates had been controlled for. The mother being unemployed and having no siblings were both significantly associated with corporal punishment, but the ORs did not remain significant through the multivariate logistic regression analyses. A child being of a younger age and studying in a special school, as well as the father's lower level of educational attainment (having achieved 
Secondary 1-7), were associated with greater odds of physical violence after controlling for covariates. Being in a family receiving public financial assistance and parents' unemployment were significantly associated with corporal punishment, but again, the ORs did not remain significant through the multivariate logistic regression analyses. 
Table 4. Demographic Characteristics Associated With Preceding-Year Corporal Punishment and Physical Violence Against a Child as Reported by Regression Analyses.

\begin{tabular}{|c|c|c|c|c|c|}
\hline \multirow[b]{2}{*}{ Characteristics } & \multirow[b]{2}{*}{$n$} & \multirow{2}{*}{$\begin{array}{l}\text { Corporal punishment } \\
\text { Crude OR }(95 \% \mathrm{Cl})\end{array}$} & \multirow{2}{*}{$\begin{array}{c}\text { Corporal } \\
\text { punishment } \\
\text { Adjusted OR } \\
(95 \% \mathrm{Cl}) \\
\end{array}$} & \multicolumn{2}{|c|}{$\begin{array}{l}\text { Physical violence against } \\
\text { Physical violence against a child a child }\end{array}$} \\
\hline & & & & Crude OR $(95 \% \mathrm{Cl})$ & Adjusted OR $(95 \% \mathrm{Cl})$ \\
\hline \multicolumn{6}{|l|}{ Age } \\
\hline $9-11$ & 1,469 & $4.95^{\star \star \star}[4.165,5.882]$ & $\begin{array}{c}6.167^{* * *}[4.762 \\
7.987]\end{array}$ & $2.341^{\star \star \star}[1.932,2.836]$ & $2.745^{\star \star \star}[2.043,3.689]$ \\
\hline $12-14$ & 2,094 & $2.315^{\star \star \star}[1.95,2.747]$ & $\begin{array}{l}2.575^{\star}[2.024 \\
\quad 3.276]\end{array}$ & $1.638^{\star \star \star}[1.359,1.974]$ & $1.983^{\star \star \star}[1.522,2.583]$ \\
\hline 15 or above & 2,278 & 1.000 & 1.000 & 1.000 & 1.000 \\
\hline \multicolumn{6}{|l|}{ Parents' marital status } \\
\hline Married & 4,920 & $1.176[0.845,1.636]$ & $\begin{array}{l}1.034[0.423 \\
2.529]\end{array}$ & $0.815[0.575,1.154]$ & $0.616[0.269,1.412]$ \\
\hline Divorced/separated & 597 & $1.446[0.994,2.103]$ & $\begin{array}{l}1.741[0.668 \\
\quad 4.541]\end{array}$ & $1.026[0.686,1.536]$ & $0.785[0.312,1.973]$ \\
\hline Widowed/single & 256 & 1.000 & 1.000 & 1.000 & 1.000 \\
\hline Have sibling & 4,552 & $0.856^{\star}[0.736,0.996]$ & $\begin{array}{l}0.870[0.693 \\
1.094]\end{array}$ & $1.007[0.839,1.209]$ & $0.924[0.710,1.203]$ \\
\hline No sibling & 1,250 & 1.000 & 1.000 & 1.000 & 1.000 \\
\hline Receiving public financial assistanc & e 526 & $1.653^{\star \star \star}[1.344,2.033]$ & $\begin{array}{l}1.650 * *[1.149 \\
2.368]\end{array}$ & $1.641^{\star \star \star}[1.293,2.082]$ & $1.443[0.965,2.158]$ \\
\hline No public financial assistance & 4,530 & 1.000 & 1.000 & 1.000 & 1.000 \\
\hline Studying in special school & 373 & $0.92[0.7,1.209]$ & $\begin{array}{l}1.106[0.688 \\
1.779]\end{array}$ & $1.333^{*}[1.001,1.776]$ & $1.639 *[1.018,2.639]$ \\
\hline Studying in ordinary school & 5,468 & 1.000 & 1.000 & 1.000 & 1.000 \\
\hline Father unemployed & 203 & $1.327[0.953,1.848]$ & $\begin{array}{l}1.006[0.628 \\
1.610]\end{array}$ & $1.457^{*}[1.001,2.122]$ & $1.064[0.632,1.791]$ \\
\hline Father employed & 4,453 & 1.000 & 1.000 & 1.000 & 1.000 \\
\hline Mother unemployed & 263 & $1.522^{\star \star}[1.147,2.02]$ & $\begin{array}{l}1.193[0.776 \\
1.834]\end{array}$ & $1.425^{\star}[1.025,1.982]$ & $1.245[0.772,2.008]$ \\
\hline Mother employed & 4,837 & 1.000 & 1.000 & 1.000 & 1.000 \\
\hline
\end{tabular}




\begin{tabular}{|c|c|c|c|c|c|}
\hline \multicolumn{6}{|l|}{ Father's educational attainment } \\
\hline Primary level or lower & 730 & $1.12[0.853,1.472]$ & $\begin{array}{c}1.171[0.775 \\
1.769]\end{array}$ & $1.32[0.948,1.838]$ & $1.317[0.803,2.161]$ \\
\hline Secondary 1-7 & 2,558 & $1.124[0.898,1.406]$ & $\begin{array}{c}1.180[0.844 \\
1.650]\end{array}$ & $1.331 *[1.009,1.757]$ & $1.540 *[1.023,2.320]$ \\
\hline Tertiary or above & 618 & 1.000 & 1.000 & 1.000 & 1.000 \\
\hline \multicolumn{6}{|l|}{ Mother's educational attainment } \\
\hline Primary level or lower & 845 & $0.971[0.724,1.301]$ & $\begin{array}{c}1.290[0.812 \\
2.049]\end{array}$ & $1.239[0.885,1.735]$ & $1.166[0.686,1.981]$ \\
\hline Secondary 1-7 & 2,802 & $1.006[0.779,1.3]$ & $\begin{array}{c}1.100[0.738, \\
1.639]\end{array}$ & $0.95[0.701,1.285]$ & $0.893[0.560,1.423]$ \\
\hline Tertiary or above & 426 & 1.000 & 1.000 & 1.000 & 1.000 \\
\hline
\end{tabular}

Note. $\mathrm{OR}=$ odds ratio; $\mathrm{Cl}=$ confidence interval.

${ }^{\star} p<.05 .{ }^{* *} p<.01 .{ }^{* \star *} p<.001$.

Table 5. Family Violence and Conflict Associated With Preceding-Year Corporal Punishment and Physical Violence Against a Child as Reported by Regression Analyses.

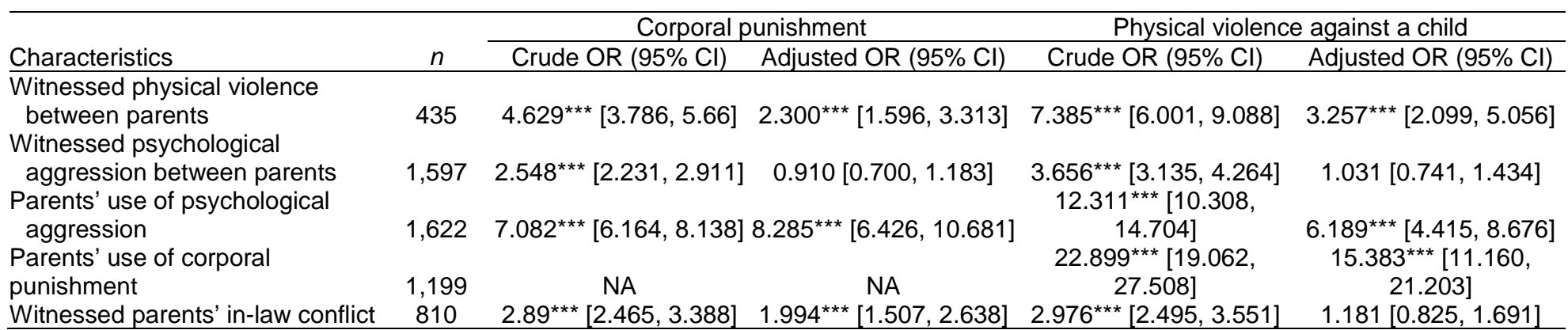

Note. Adjusted OR calculated by controlling all demographic variables in Table 4. OR = odds ratio; $\mathrm{Cl}=$ confidence interval.

${ }^{\star} p<.05 .{ }^{* *} p<.01 .{ }^{* \star *} p<.001$. 
Table 5 presents the results of logistic regression analyses examining the correlation of IPV, in-law conflict, and CM. Exposure to physical violence between parents (adjusted odds ratio $[\mathrm{aOR}]=2.300,95 \%$ confidence interval $[\mathrm{CI}]=[1.596,3.313])$, parents' in-law conflict $(\mathrm{aOR}=1.994,95 \% \mathrm{CI}=[1.507,2.638])$, and parents' use of psychological aggression $(\mathrm{aOR}=8.285,95 \% \mathrm{CI}=[6.426,10.681])$ were factors significantly associated with parents' use of corporal punishment after controlling for all the demographic covariates listed in Table 4. In examining the factors associated with such physical violence, exposure to physical IPV $(\mathrm{aOR}=3.257,95 \% \mathrm{CI}=[2.099,5.056])$ was a significant factor after controlling for all the demographic covariates. Parents' use of psychological aggression $(\mathrm{aOR}=6.189,95 \% \mathrm{CI}=[4.415,8.676])$ and corporal punishment $(\mathrm{aOR}=15.383,95 \% \mathrm{CI}=[11.160,21.203])$ against a child resulted in increased odds of physically abusing him or her. Psychological aggression between parents and parents' in-law conflict were significantly associated with physical violence, but the ORs did not remain significant through the multivariate logistic regression analyses.

\section{Discussion}

Although extant research suggests that IPV and CM frequently co-occur, these conclusions are largely based on research with clinical samples and the reports of adult subjects. Using children as informants, this study indicates lifetime and preceding-year prevalence rates of co-occurrence of $12.3 \%$ and $3.6 \%$, respectively. Among those families characterized by physical violence between parents, $64.7 \%$ and $48 \%$ were involved in physical violence against a child in their lifetime and the preceding year of the study, respectively. These rates are comparable with previous studies in Canada (Bourassa, 2007) and the United States (Finkelhor et al., 2007, 2009; Margolin et al., 2009). The gender differences in children's reports of physical violence against them are in line with other research suggesting that boys are at greater risk of experiencing physical violence than girls (Grych et al., 2000; Jouriles \& Norwood, 1995; Le \& Wallen, 2009; Ross, 1996; Tang, 2006). The reasons for this may be attributed to the different behavioral expectations for boys and girls and the importance parents place on socializing their sons into the masculine gender role (Tang, 2006). Moreover, research also suggests that there are gender differences in reactions to witnessing IPV. Boys tend to act out to divert attention from their parents' marital conflict, whereas girls may try to behave extremely well so as to avoid any interactions with their parents which might place a further burden on the marital relationship (Jouriles \& Norwood, 1995). As a result of such acting-out and its potential for aggressive behavior, boys are more likely to be physically abused by parents. The rates for parents' use of CM, in-law conflict, and IPV were similar for both parents in the present study, which was a finding different from previous research showing that fathers were the main perpetrators of IPV against mothers (Arias \& Corso, 2005; Phelan et al., 2005). However, it seems to be consistent with studies conducted by Straus (2006). Johnson (1995) pointed out that studies using representative samples of married, cohabiting, and dating couples could reveal very different results from those using women from refuges or men in violence treatment programs. 
This study shows that psychological aggression and corporal punishment against a child are behaviors commonly used by parents. This is consistent with research based on women's self-reports (English et al., 2009). However, it is important to be aware that children's exposure to parental psychological aggression is not necessarily harmless. Research has found that exposure to psychological aggression between parents predicts poor emotion regulation and, specifically, increases the likelihood that infants will withdraw from novel stimuli (Crockenberg, Leerkes, \& Lekka, 2007). Furthermore, children experiencing psychological aggression committed by parents also tend to display increased aggression and social withdrawal in middle childhood and decreased social competence in early adolescence (Shaffer, Yates, \& Egeland, 2009). This study also shows that parents' use of psychological aggression and corporal punishment against a child were significantly associated with physical violence against that child. Given this correlation, and the high prevalence rates of the former, prevention of CM should begin at an earlier stage, namely, when corporal punishment takes place. In Hong Kong, there are laws prohibiting corporal punishment against a child by teachers and child care service providers, but not by parents. Parents' use of corporal punishment is endorsed in Chinese culture. A ban on corporal punishment by parents explicitly through law reform has been urged by child rights advocates. The outlawing of corporal punishment has become a global movement that is believed to be effective in preventing child abuse (Pinheiro, 2006).

The data presented in this study support the notion that there is a strong association between IPV and CM (C. Casanueva, Kotch, \& Zolotor, 2007; C. Casanueva, Martin, \& Runyan, 2009; Herrenkohl \& Herrenkohl, 2007; Herrenkohl, Sousa, Tajima, Herrenkohl, \& Moylan, 2008). The presence of IPV, particularly physical violence, predicts the occurrence of CM within the same nuclear family. In addition, this study demonstrates a correlation between in-law conflict and the use of corporal punishment against a child.

IPV may be a possible mediator of the association between in-law conflict and corporal punishment. Previous research has found that the former is a significant risk factor for IPV (Chan et al., 2008; Chan et al., 2009). It may be suggested that Chinese women are socialized to identify with men and their interests, so it is very common for a mother-in-law to collude with her son in disciplining his wife (Chan et al., 2009). Consequently, a mother-in-law could be a perpetrator of in-law conflict in an attempt to support the superior role of a man within the family (Chan et al., 2008). The stress and conflict involved where there is in-law conflict are likely to intensify the spousal relationship. As shown in previous research, a negative marital interaction may spill over into the parent-child relationship and result in harsh and aggressive punishment of the child (Holden, Stein, Ritchie, Harris, \& Jouriles, 1998; O’Keefe, 1995). IPV stresses the marital relationship and reduces parental capacity, meaning the parent is more likely to resort to disciplining the child through acts of physical violence (Bourassa, 2007). Thus, the association between in-law conflict and corporal punishment against children can be mediated by IPV.

There are several limitations to this study, which should be noted. First, the results are largely based on cross-sectional data, which only enable correlation and not causality to be established. Consequently, inferences that IPV and in-law conflict are the causes of CM 
cannot be confirmed. Second, the timing of the occurrence of the various forms of violence was not addressed in the present study. It may be that a child is physically abused by parents in advance of witnessing IPV between them, rather than the reverse. The temporal order of IPV and the occurrence of specific forms of CM should be examined in future research. Third, the present study only controlled for demographic characteristics such as age, level of education, marital status, unemployment and educational attainment, financial circumstances, and number of siblings. However, it is possible that other factors such as alcohol use, approval of violence, and parents' health may be also associated with family violence. Future research should also analyze these factors in examining the association between IPV and CM.

Despite these limitations, the present study has addressed factors associated with $\mathrm{CM}$ based on a representative population sample. Previous studies have usually been conducted using clinical samples which limits the generalizability of the results (Edleson, 1999). Self-selected samples also are not applicable to the general population. This study provides information on the extent to which IPV is related to physical violence in the population as a whole, and consequently could be useful to government, the police, and social service agencies seeking to tackle various forms of family violence. It could also help judges and court mediators make custody decisions when either or both parents have physically abused his or her partner and children.

The co-occurrence rate also highlights the need for a comprehensive assessment approach to family violence in homes. By examining the different characteristics and risk factors associated with IPV and CM, a more complete understanding of the behavior involved in family violence can be achieved, which will be useful in creating effective interventions for each family member in homes where domestic violence has occurred. Services should address the needs of children who have witnessed IPV, experienced CM, or have been exposed to both. Children who experience both CM and IPV are likely to report more severe behavioral and emotional problems than those exposed to a single type of violence (Finkelhor et al., 2009). Training for assessing effective responses to both CM and IPV is necessary for both child protective service workers and domestic violence agencies. As well as addressing marital relationships in an attempt to reduce spousal conflict, an assessment of families with dual violence should also include education for parents. They should be taught to use alternatives to aggression, such as timeouts and negotiation, in managing their children's behavior. Effective parenting can reduce parents' use of physical aggression toward a child. This study provides preliminary evidence that there is a correlation between in-law conflict and the use of corporal punishment against a child. It seems that in-law conflict is a common phenomenon among Chinese and some Asian cultures. It could be part of the family culture or practice that makes violence difficult to eliminate. For that reason, to break the cycle of violence within the family, child protection services and domestic violence agencies should work together to offer a careful screening for child victims in the context of domestic violence. Family-based interventions such as home visitations (Olds et al., 1999) for child victims with the consideration of coexistence of multiple forms of violence within the same nuclear family should therefore be implemented. 


\section{Acknowledgment}

The author would like to acknowledge the support of this research by the Hong Kong Committee for UNICEF.

\section{Declaration of Conflicting Interests}

The author(s) declared no potential conflicts of interest with respect to the research, authorship, and/or publication of this article.

\section{Funding}

The author(s) received financial support for the research from the Hong Kong Committee for UNICEF..

\section{References}

Appel, A. E., \& Holden, G. W. (1998). The co-occurrence of spouse and physical child abuse: A review and appraisal. Journal of Family Psychology, 12, 578-599.

Arias, I., \& Corso, P. (2005). Average cost per person victimized by an intimate partner of the opposite gender: A comparison of men and women. Violence and Victims, 20, 379-391.

Bourassa, C. (2007). Co-occurrence of interparental violence and child physical abuse and its effect on the adolescents' behavior. Journal of Family Violence, 22, 691-701.

Carlson, B. E. (1991). Outcomes of physical abuse and observation of marital violence among adolescents in placement. Journal of Interpersonal Violence, 6, 526-534.

Casanueva, C., Kotch, J., \& Zolotor, A. (2007). Intimate partner violence and child abuse and neglect. In K. A. Kendall-Tackett \& S. M. Giacomoni (Eds.), Intimate partner violence (pp. 23-1-23-17). Kingston, NJ: Civic Research Institute.

Casanueva, C., Martin, S. L., \& Runyan, D. K. (2009). Repeated reports for child maltreatment among intimate partner violence victims: Findings from the National Survey of Child and Adolescent Well-Being. Child Abuse \& Neglect, 33, 84-93.

Casanueva, C. E., \& Martin, S. L. (2007). Intimate partner violence during pregnancy and mothers' child abuse potential. Journal of Interpersonal Violence, 22, 603-622.

Chaffin, M. (2006). The changing focus of child maltreatment research and practice within psychology. Journal of Social Issues, 62, 663-684.

Chan, K. L. (2005). Study on child abuse and spouse battering: Report on findings of household survey (A Consultancy Study Commissioned by the SWD of HKSAR). Hong Kong: Department of Social Work \& Social Administration, The University of Hong Kong.

Chan, K. L. (2009a). Protection of face and avoidance of responsibility: Chinese men's account of violence against women. Journal of Social Work Practice, 23, 93-108.

Chan, K. L. (2009b). Sexual violence against women and children in Chinese societies. Trauma, Violence, \& Abuse, 10, 69-85.

Chan, K. L., Brownridge, D. A., Tiwari, A., Fong, D. Y. T., \& Leung, W. C. (2008). Understanding violence against Chinese women in Hong Kong: An analysis of risk factors with a special emphasis on the role of in-law conflict. Violence Against Women, 14, 1295-1312.

Chan, K. L., Tiwari, A., Fong, D. Y. T., Leung, W. C., Brownridge, D. A., \& Ho, P. C. (2009). Correlates of in-law conflict and intimate partner violence against Chinese pregnant women in Hong Kong. Journal of Interpersonal Violence, 24, 97-110. 
Crockenberg, S. C., Leerkes, E. M., \& Lekka, S. K. (2007). Pathways from marital aggression to infant emotion regulation: The development of withdrawal in infancy. Infant Behavior and Development, 30, 97-113.

Dixon, L., Hamilton-Giachritsis, C., Browne, K., \& Ostapuik, E. (2007). The co-occurrence of child and intimate partner maltreatment in the family: Characteristics of the violent perpetrators. Journal of Family Violence, 22, 675-689.

Edleson, J. L. (1999). The overlap between child maltreatment and woman battering. Violence Against Women, 5, 134-154.

English, D. J., Graham, J. C., Newton, R. R., Lewis, T. L., Thompson, R., Kotch, J. B., \& Weisbart, C. (2009). At-risk and maltreated children exposed to intimate partner aggression/violence: What the conflict looks like and its relationship to child outcomes. Child Maltreatment, 14, 157-171.

Finkelhor, D., Ormrod, R. K., \& Turner, H. A. (2007). Poly-victimization: A neglected component child victimization. Child Abuse \& Neglect, 31, 7-26.

Finkelhor, D., Ormrod, R. K., \& Turner, H. A. (2009). Lifetime assessment of poly-victimization in a national sample of children and youth. Child Abuse \& Neglect, 33, 403-411.

Grych, J. H., Jouriles, E. N., Swank, P. R., McDonald, R., \& Norwood, W. D. (2000). Patterns of adjustment among children of battered women. Journal of Consulting and Clinical Psychology, 68, 84-94.

Herrenkohl, T. I., \& Herrenkohl, R. C. (2007). Examining the overlap and prediction of multiple forms of child maltreatment, stressors, and socioeconomic status: A longitudinal analysis of youth outcomes. Journal of Family Violence, 22, 553-562.

Herrenkohl, T. I., Sousa, C., Tajima, E. A., Herrenkohl, R. C., \& Moylan, C. A. (2008). Intersection of child abuse and children's exposure to domestic violence. Trauma, Violence, \& Abuse, 9, 84-99.

Ho, C. (1990). An analysis of domestic violence in Asian American communities: A multicultural approach to counseling. Women \& Therapy, 9, 129-150.

Holden, G. W., Stein, J. D., Ritchie, K. L., Harris, S. D., \& Jouriles, E. N. (1998). Introduction. In G. W. Holden, R. Geffner, \& E. N. Jouriles (Eds.), Children exposed to marital violence: Theory, research, and applied issues (pp. 289-234). Washington, DC: American Psychological Association.

Johnson, M. P. (1995). Patriarchal terrorism and common couple violence: Two forms of violence against women. Journal of Marriage \& the Family, 57, 283-294.

Jouriles, E. N., McDonald, R., Slep, A. M. S., Heyman, R. E., \& Garrido, E. (2008). Child abuse in the context of domestic violence: Prevalence, explanations, and practice implications. Violence and Victims, 23, 221-235.

Jouriles, E. N., \& Norwood, W. D. (1995). Physical aggression toward boys and girls in families characterized by the battering of women. Journal of Family Psychology, 9, 69-78.

Le, T. N., \& Wallen, J. (2009). Risks of non-familial violent physical and emotional victimization in four Asian ethnic groups. Journal of Immigrant Minority Health, 11, 174-187.

Leung, P. W. S., Wong, W. C. W., Chen, W. Q., \& Tang, C. S. K. (2008). Prevalence and determinants of child maltreatment among high school students in Southern China: A large scale school based survey. Child and Adolescent Psychiatry and Mental Health, 2, 27-34.

Margolin, G., \& Gordis, E. B. (2000). The effects of family and community violence on children. Annual Review of Psychology, 51, 445-479.

Margolin, G., Gordis, E. B., Medina, A. M., \& Oliver, P. H. (2003). The co-occurrence of husbandto-wife aggression, family-of-origin aggression, and child abuse potential in a community sample: Implications for parenting. Journal of Interpersonal Violence, 18, 413-440. 
Margolin, G., Vickerman, K. A., Ramos, M. C., Serrano, S. D., Gordis, E. B., Iturralde, E., et al. (2009). Youth exposed to violence: Stability, co-occurrence, and context. Clinical Child and Family Psychology Review, 12, 39-54.

McGuigan, W. M., \& Pratt, C. C. (2001). The predictive impact of domestic violence on three types of child maltreatment. Child Abuse \& Neglect, 25, 869-883.

O’Brien, R. M. (2007). A caution regarding rules of thumb for variance inflation factors. Quality \& Quantity, 41, 673-690.

O'Keefe, M. (1995). Predictors of child-abuse in maritally violent families. Journal of Interpersonal Violence, 10, 3-25.

Olds, D. L., Henderson, C. R., Kitzman, H. J., Eckenrode, J. J., Cole, R. E., \& Tatelbaum, R. C. (1999). Prenatal and infancy home visitation by nurses: Recent findings. Future of Children, 9, 44-65.

Phelan, M. B., Hamberger, L. K., Guse, C. E., Edwards, S., Walczak, S., \& Zosel, A. (2005). Domestic violence among male and female patients seeking emergency medical services. Violence and Victims, 20, 187-206.

Pinheiro, P. S. (2006). United Nations Secretary-General's study on violence against children (World report on violence against children). Geneva, Switzerland: ATAR Roto Presse SA.

Ross, S. M. (1996). Risk of physical abuse to children of spouse abusing parents. Child Abuse \& Neglect, 20, 589-598.

Shaffer, A., Yates, T. M., \& Egeland, B. R. (2009). The relation of emotional maltreatment to early adolescent competence: Developmental processes in a prospective study. Child Abuse \& Neglect, 33, 36-44.

Shipman, K. L., Rossman, B. B., \& West, J. C. (1999). Co-occurrence of spousal violence and child abuse: Conceptual implications. Child Maltreatment, 4, 93-102.

Slep, A. M. S., \& O’Leary, S. G. (2005). Parent and partner violence in families with young children: Rates, patterns, and connections. Journal of Consulting and Clinical Psychology, 73, 435-444.

Straus, M. A. (2006). Future research on gender symmetry in physical assaults on partners. Violence Against Women, 12, 1086-1097.

Straus, M. A., \& Hamby, S. L. (1997). Measuring physical and psychological maltreatment of children with the Conflict Tactics Scales. In G. Kaufman Kantor \& J. L. Jasinski (Eds.), Out of the darkness: Contemporary research perspectives on family violence (pp. 119-135). Thousand Oaks, CA: SAGE.

Straus, M. A., Hamby, S. L., Finkelhor, D., Moore, D. W., \& Runyan, D. (1998). Identification of child maltreatment with the Parent-Child Conflict Tactics Scales: Development and psychometric data for a national sample of American parents. Child Abuse \& Neglect, 22, 249-270.

Tang, C. S. K. (2006). Corporal punishment and physical maltreatment against children: A community study on Chinese parents in Hong Kong. Child Abuse \& Neglect, 30, 893-907.

\section{Author Biography}

Ko Ling Chan is with the Department of Social Work and Social Administration, University of Hong Kong, Hong Kong. 